\title{
Detection of Heavy Metal Tolerance among different MLSB Resistance Phenotypes of Methicillin-Resistant S. aureus (MRSA)
}

\author{
Sara H. Mohamed ${ }^{1}\left(\mathbb{D}\right.$, Maram M.S. Elshahed ${ }^{1}{ }^{(D)}$ Yasmine M. Saied $^{1}{ }^{(D)}$, \\ Mahmoud S.M. Mohamed ${ }^{2 *}$ (D) and Gamal H. Osman ${ }^{3,4,5}$ \\ ${ }^{1}$ Department of Microbiology, National Organization for Drug Control and Research, Giza, Egypt. ${ }^{2}$ Department of \\ Botany and Microbiology, Faculty of Science, Cairo University, 12613, Giza, Egypt. ${ }^{3}$ Department of Biology, Faculty \\ of Applied Science, Umm Al-Qura University, Makkah, Saudi Arabia. ${ }^{4}$ Research Laboratories Center, Faculty of \\ Applied Science, Umm Al-Qura University, Makkah, Saudi Arabia. ${ }^{5}$ Agricultural Genetic Engineering Research \\ Institute (AGERI), ARC, 12619, Giza, Egypt.
}

\begin{abstract}
Methicillin-resistant Staphylococcus aureus (MRSA) strains are widespread globally. Besides their virulence factors, the co-occurrence of antimicrobial and metal resistance has been reported. This study was designed to evaluate the antibiotic resistance and resistance phenotypes, investigate the occurrence of virulence factors, and detect heavy metal tolerance among MRSA strains. Antibiogram profiling was done as recommended by CLSI instructions. Resistance phenotypes were detected by D test, followed by characterization of enzymatic activities and biofilm formation assay. Antibacterial activity of different heavy metals was tested, and predictable synergistic assay was performed. Among MRSA strains collected, high resistance to ampicillin and amoxicillin/clavulanate (100\%) and high susceptibility to clindamycin (70\%) were obtained. Resistance phenotypes were detected as $\mathrm{S}$, constitutive MLSB, inducible MLSB, and MS by percentages of $10 \%, 30 \%, 30 \%$ and $30 \%$ respectively. Virulence factors like lipolytic (50\%) and hemolytic (70\%) activity, and biofilm formation ability (100\%) were detected. High resistance towards potassium and magnesium was observed. MTC of 500 ppm was detected for all isolates in case of cobalt and iron. In case of zinc and copper, MTC was detected as $500 \mathrm{ppm}$ except for one isolate which was highly resistant, and $500 \mathrm{ppm}$ for all isolates except for two isolates which were highly sensitive respectively. Magnesium in different concentrations (500 and 2000 ppm) showed synergistic activity with erythromycin and clindamycin. Results reveal high heavy metal tolerance among antibiotic resistant MRSA strains, in addition to the presence of virulence factors. Upcoming studies must be focused on the combination of sub-inhibitory concentration of different heavy metals with the available antibiotics.
\end{abstract}

Keywords: MRSA, biofilm, MLSB, heavy metals, S. aureus

*Correspondence: msaleh@sci.cu.edu.eg (M.S.M.M.)

(Received: June 14, 2020; accepted: September 02, 2020)

Citation: Mohamed SH, Elshahed MMS, Saied YM, Mohamed MSM, Osman GH. Detection of Heavy Metal Tolerance among different MLSB Resistance Phenotypes of Methicillin-Resistant S. aureus (MRSA). J Pure Appl Microbiol. 2020;14(3):1905-1916. doi: 10.22207/JPAM.14.3.29

(C) The Author(s) 2020. Open Access. This article is distributed under the terms of the Creative Commons Attribution 4.0 International License which permits unrestricted use, sharing, distribution, and reproduction in any medium, provided you give appropriate credit to the original author(s) and the source, provide a link to the Creative Commons license, and indicate if changes were made. 


\section{INTRODUCTION}

Staphylococcus aureus is a bacterial pathogen, which is considered as one of the most common agents in a variety of human infections including skin, soft tissue as well as eye ${ }^{1}$. Those bacterial species shows some virulence factors which are tightly regulated specially during bacterial growth and pathogenesis process ${ }^{2}$.

Formation of biofilms is one of the important virulence factors that provide hard bacterial growth mode making them resist the unfavorable conditions more than those without biofilms ${ }^{3}$. A central role in the regulation of such virulence is controlled by bacterial quorumsensing system ${ }^{4}$. Bacterial biofilm formation ability always allow more advantages for bacterial cell survival compared to planktonic growth, including protection from shear stress, disinfectants, and antibiotics by its special structure ${ }^{5-7}$. This mode of bacterial growth induces cellular dormancy associated with multidrug tolerance, and nonheritable phenotype that differs from classic mechanisms of antibiotic resistance ${ }^{8,9}$.

Resistance to antimicrobial agents has become a difficult problem all over the world ${ }^{10,11}$. Nowadays, the emergence of methicillin-resistant S. aureus (MRSA) became a great concern as it causes life-threatening nosocomial and community-acquired infections ${ }^{12}$. Due to the limited number of effective antibiotics, treatment of such infections is sometimes considered very difficult ${ }^{13}$. S. aureus isolates qualify to have a resistance to erythromycin which is commonly associated with resistance to other macrolides. Three genes were found in $S$. aureus responsible for this resistance viz. ermA, ermB and ermC, and encode methylase enzymes which have a role in modifying the ribosomal target site leading to $S$. aureus MLSB phenotype ${ }^{14}$.

Treatment of patients infected with $S$. aureus with clindamycin harboring inducible clindamycin resistance (iMLSb phenotype) might lead to the evolution of resistant strains (cMLSB) and subsequently, causing more therapeutic failure $^{15}$. Erythromycin and clindamycin are different classes of antibiotics which bind to the 505 ribosomal subunit of bacteria and inhibit protein synthesis. S. aureus resistance to these antibiotics is created by methylation of the target site on the ribosome mostly related to methylase gene erm $(\text { rRNA })^{16}$.

The widespread metal contamination of human surrounding is considered a recalcitrant selection pressure in bacteria with clinical and environmental importance that donates some antibiotic resistance factors ${ }^{17}$. Indeed, bacteria are continually changing their genetic compositions, which makes them able to adapt and alter their living conditions. Therefore, the heavy metalinduced bacterial resistance plays an important role in the development of bacteria ${ }^{18}$ and may play an important role in disseminating bacterial antibiotic resistance, but the selective effects of heavy metals on bacterial antibiotic resistance are largely unclear. To investigate this, the effects of heavy metals on antibiotic resistance were studied in a genome-sequenced bacterium, LSJC7. The results showed that the presence of arsenate, copper, and zinc were implicated in fortifying the resistance of LSJC7 towards tetracycline. The concentrations of heavy metals required to induce antibiotic resistance, i.e., the minimum heavy metal concentrations (MHCs. Much like antibiotics, heavy metals often have toxic effects on bacteria. Therefore, due to their antimicrobial properties, they are mostly incorporated into products ${ }^{19}$.

Through our investigation, we evaluated the antibiotics resistance of ten clinical $S$. aureus isolates, besides detection of their MLBS phenotypes. The heavy metal tolerance among antibiotic-resistant MRSA strains was investigated. In addition, the occurrence of $S$. aureus virulence factors such as biofilm formation ability as well as hemolytic and lipolytic activities were assessed.

\section{MATERIALS AND METHODS Bacterial strains}

Ten S. aureus isolates used in the current study were collected from El-Kasr el Ainy hospital, Cairo, Egypt. Initially, the strains of $S$. aureus were identified using traditional biochemical tests including Gram staining, catalase, coagulase (both slide and tube), and DNase tests, and confirmed by growing in selective Mannitol Salt Agar (MSA) medium ${ }^{20}$.

\section{Antibiogram profiling}

Antibiotic sensitivity was performed by using the standard disk diffusion method on Muller- 
Hinton (MH; Laboratories Conda SA, Madrid, Spain) agar plate according to recommended CLSI guidelines ${ }^{21}$. Standard antimicrobial disks (Oxoid, Basingstoke, UK) representing seven different drug classes such as amikacin (30 $\mu \mathrm{g})$, ciprofloxacin (5 $\mu \mathrm{g})$, amoxicillin/clavulanic $(30 \mu \mathrm{g})$, cefoxitin (FOX), sulphamethoxazole-trimethoprim (1.25/23.75 $\mu \mathrm{g})$, ampicillin $(10 \mu \mathrm{g})$, erythromycin $(15 \mu \mathrm{g})$, and clindamycin $(2 \mu \mathrm{g})$ were used.

Detection of Macrolide-LincosamideStreptogramin B (MLSB) resistance phenotypes

MLSB resistance pattern was evaluated for all $S$. aureus isolates using the D-test ${ }^{13}$. At a distance of $15 \mathrm{~mm}$ (edge to edge), erythromycin $(15 \mu \mathrm{g})$ and clindamycin $(2 \mu \mathrm{g})$ discs were placed on $\mathrm{MH}$ agar plate which was previously inoculated with 0.5 MacFarland bacterial suspensions. Following overnight incubation at $37^{\circ} \mathrm{C}$, D shaped zone formed around clindamycin in the area between the two discs indicated positive result. The results were interpreted as erythromycinsensitive, clindamycin-sensitive (S); erythromycinresistant, clindamycin-resistant (constitutive MLSB); erythromycin-resistant, clindamycinsensitive, D-test positive (inducible MLSB); erythromycin-resistant, clindamycin-sensitive, D-test negative $(\mathrm{MS})^{22}$.

Characterization of the $S$. aureus enzymatic activity

Lipolytic activity was carried out using agar plates containing tween $20(1 \% \mathrm{v} / \mathrm{v})$ as described previously ${ }^{23}$. The plates were inoculated with a single colony of a culture on nutrient agar and incubated for (1-5) days at $37^{\circ} \mathrm{C}$. The turbid zone around colonies, with the change to blue color after the addition of a saturated solution of $\mathrm{CuSO}_{4} \cdot 5 \mathrm{H}_{2} \mathrm{O}$ reagent, indicates a positive result.

Hemolysis test on blood agar with defibrinated sheep blood $5 \%$ (v/v) was used. Isolates were inoculated and incubated for a day at $37^{\circ} \mathrm{C}$. After incubation, the formation of zones around the bacterial growth was detected and characterized as $\alpha$ (partial hemolysis), $\beta$ (complete hemolysis), and $\gamma$ (no hemolysis) depending on the activities of each bacterial strain ${ }^{24}$.

\section{Microtiter plate biofilm assay}

In order to perform the biofilm assay, wells of the 96 polystyrene plate were first filled with $100 \mu$ l of the bacteria inoculated in Brain
Heart Infusion broth, at which uninoculated broth was considered as negative control. After 24 hours incubation at $37^{\circ} \mathrm{C}$, the contents of wells were gently removed. The wells were washed as recommended, dried, and the adherent bacteria biofilms formed were then stained with $1 \%$ aqueous solution of crystal violet (CV). After 10 minutes, excess stain was washed gently, and the plate was kept for drying. To solubilize the stained adherent biofilm, absolute ethanol was used ${ }^{25}$.

By using an auto-reader (Stat Fax-2100; GMI, Inc. USA), the optical density was measured at a wavelength of $570 \mathrm{~nm}$. Each experiment was performed three times. Optical density cut-off value (O.Dc) was calculated as mentioned ${ }^{7}$.

Antibacterial effect of antibiotics against bacterial isolates

Antibacterial activity assay of antibiotics was carried out by microtiter broth dilution method $^{26}$. As a diluent, $\mathrm{MH}$ broth was used, where about $10^{6} \mathrm{CFU} / \mathrm{mL}$ cells (0.5 MacFarland bacterial cultures) were inoculated, at which the final volume in each microtiter plate well was $100 \mu \mathrm{l}$ and antibiotics concentration ranged from $0.25-16 \mu \mathrm{l} / \mathrm{ml}, 0.06-4 \mu \mathrm{l} / \mathrm{ml}$, and 0.125-8 $\mu \mathrm{l} / \mathrm{ml}$ for gentamycin, ciprofloxacin, and erythromycin respectively. After 24 hours incubation at $37^{\circ} \mathrm{C}$, the minimum inhibitory concentration (MIC) values, defined as the lowest antibiotic concentration which inhibited visual bacterial growth, were measured.

Detection of heavy metals/essential elements maximum tolerance concentration (MTC)

The MTC values of heavy metals/ essential elements for the bacterial isolates were determined by agar dilution method, using nutrient agar supplemented with different heavy metals like: copper $\left(\mathrm{Cu}^{2+}\right)$, cobalt $\left(\mathrm{Co}^{2+}\right)$, zinc $\left(\mathrm{Zn}^{2+}\right)$ and iron $\left(\mathrm{Fe}^{2+}\right)$, and different essential elements like: potassium $\left(\mathrm{K}^{+}\right)$and magnesium $\left(\mathrm{Mg}^{2+}\right)$. The concentrations of the utilized metals included: 500 , 1500 and 2000 ppm. After 18 hours incubation at $37^{\circ} \mathrm{C}$, the MTC, defined as the highest metal/ element concentration that allow the bacterial growth, were measured ${ }^{27}$.

\section{Effect of biofilm formation}

The antibiofilm activity of different antibiotics at sub-inhibitory concentrations was done as described with minor modifications ${ }^{28}$. In 
case of no MIC detected, the $1 / 2$ MIC represents the highest antibiotic concentration. $100 \mu$ l of bacterial suspension ( $0.5 \mathrm{McF}$ arland) were dispensed into each well of 96-well polystyrene microtiter plates, and different antibiotic concentrations $(100 \mu \mathrm{l})$ were added, and plates were incubated at $37^{\circ} \mathrm{C}$ for 18 hours. Antibiotic free wells (biofilm growth) act as positive controls. After incubation, the medium and non-adherent cells were removed and wells were washed three times with sterile PBS. The plates were well dried and then the dye was resolubilized with absolute ethanol. The OD of each well was measured at $570 \mathrm{~nm}$ using ELISA reader. Each assay was performed in duplicates.

The antibiotic/ potassium ( $\mathrm{K}+$ ) and magnesium (Mg2+) synergistic assay

Synergistic activity was assessed by using the agar disk diffusion method using antibiotic disks of erythromycin $(15 \mu \mathrm{g})$, and clindamycin $(2 \mu \mathrm{g})$. $\mathrm{MH}$ agar supplemented with different elements; $\mathrm{K}^{+}$and $\mathrm{Mg}^{2+}$ concentrations was used. The bacterial inoculum of 0.5 McFarland concentrations was applied on the surface of the agar plate and antibiotic disks were placed onto the inoculated agar surface. After incubation for 18 hours at $37^{\circ} \mathrm{C}$, the zones of growth inhibition around each of the antibiotic disks were measured. $\mathrm{MH}$ agar plates without $\mathrm{K}^{+}$and $\mathrm{Mg}^{2+}$ supplementation were considered as negative control ${ }^{6}$.

\section{Statistical analysis}

Chi-square test $\left(\chi^{2}\right)$ was conducted to analyze the significance of the resistance level to various antibiotics. A value of $p<0.05$ was considered to be statistically significant. The calculated mean values are presented with standard deviation (SD) bars using the Duncan test using SPSS software (Statistical Package for the Social Sciences, ver. 12.0, New York)

\section{RESULTS}

\section{Antibiogram profiling}

In this study, ten methicillin-resistant S. aureus bacterial isolates were used. The sensitivity test was performed using the KirbyBauer antibiogram method using antibiotic discs representing seven different classes of antibiotics and results were interpreted according to CLSI. Results presented in Table (1) showed that high resistance to ampicillin and amoxicillin/clavulanic by percentages of $100 \%$ was obtained. On the other hand, clindamycin was found to be the most effective antibiotic against the isolates with $70 \%$ of strains exhibiting sensitivity to this drug (Table 1).

\section{Detection of MLSB resistance phenotypes}

Resistant phenotypes among $S$. aureus strains were detected using $D$ test. Different resistance phenotypes were detected as

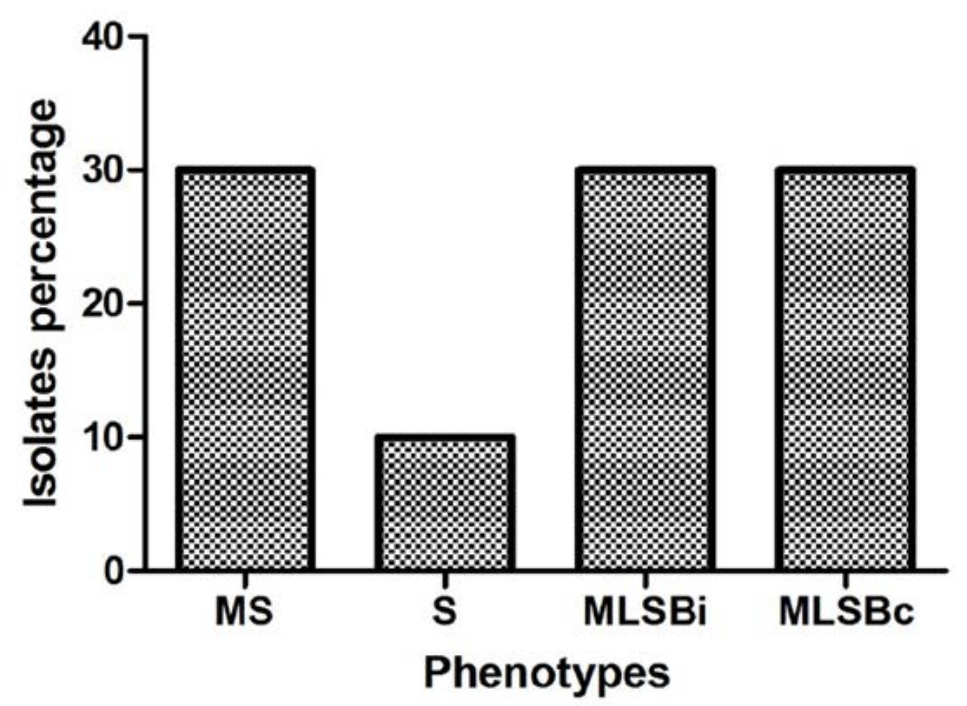

Fig. 1. Resistant phenotypes among S. aureus strains. Erythromycin-sensitive, Clindamycin-sensitive (S); Erythromycinresistant, Clindamycin-resistant (constitutive MLSB); Erythromycin-resistant, Clindamycin-sensitive, D-test positive (inducible MLSB); Erythromycin-resistant, Clindamycin-sensitive, D-test negative (MS). 
constitutive MLSB, inducible MLSB, S, and MS by percentages of $10 \%, 30 \%, 30 \%$ and $30 \%$ respectively (Fig. 1).

Characterization of the enzymatic activity and biofilm formation ability

The virulence factors of MRSA including lipolytic and hemolytic activity were tested among the ten strains (Table 2), the results showed that $50 \%$ of isolates had lipolytic activity, whereas $70 \%$ of them had hemolytic activity. Regarding the biofilm formation of MRSA, it was observed that all tested isolates were capable of producing biofilm and most of the isolates (70\%) forms strong biofilms while $30 \%$ were categorized as moderate biofilm formers (Table 2).

Minimum inhibitory concentrations of different antibiotics

The susceptibility of three antibiotics (gentamycin, ciprofloxacin and erythromycin) was confirmed using micro-broth dilution method (Table 3). High resistance rates among tested MRSA strains were observed.

\section{Detection of heavy metals maximum tolerance} concentration (MTC)

Detection of heavy metals MTC was performed using $\mathrm{MH}$ supplemented with three

Table 1. antibiotic susceptibility pattern among MRSA isolates

\begin{tabular}{|c|c|c|c|c|c|c|}
\hline \multirow{3}{*}{ Antibiotic class } & \multirow{3}{*}{ Antibiotics } & \multicolumn{4}{|c|}{ Antibiogram profile } & \multirow{3}{*}{$p$-value* } \\
\hline & & \multicolumn{2}{|c|}{ Resistant } & \multicolumn{2}{|c|}{ Non resistant } & \\
\hline & & No. & $\%$ & No. & $\%$ & \\
\hline Aminoglycosides & Amikacin & 5 & 50 & 5 & 50 & 0.740 \\
\hline \multirow[t]{2}{*}{$\beta$-lactam } & Cefoxitin & 10 & 100 & 0 & 0 & - \\
\hline & Amoxicillin/clavulanic & 10 & 100 & 0 & 0 & - \\
\hline Fluoroquinolones & Ciprofloxacin & 8 & 80 & 2 & 20 & 0.678 \\
\hline Sulphonamides & $\begin{array}{l}\text { Sulphamethoxazole- } \\
\text { trimethoprim }\end{array}$ & 3 & 30 & 7 & 70 & 0.717 \\
\hline Aminopenicillins & Ampicillin & 10 & 100 & 0 & 0 & - \\
\hline Macrolide & Erythromycin & 9 & 90 & 1 & 10 & 0.580 \\
\hline Lincosamide & Clindamycin & 3 & 30 & 7 & 70 & 0.717 \\
\hline
\end{tabular}

*A value of $p<0.05$ was considered to be statistically significant.

Table 2. Virulence factors and resistance phenotypes assessment among S. aureus stains.

\begin{tabular}{|c|c|c|c|c|c|}
\hline \multirow{3}{*}{ Strains } & \multicolumn{5}{|c|}{ Virulence factors } \\
\hline & \multirow{2}{*}{$\begin{array}{c}\text { MLSB resistance } \\
\text { phenotypes }\end{array}$} & \multicolumn{2}{|c|}{ Enzymatic activity } & \multicolumn{2}{|c|}{$* *$ Biofilm formation } \\
\hline & & $\begin{array}{l}\text { *Lipolytic } \\
\text { activity }\end{array}$ & $\begin{array}{l}\text { Hemolytic } \\
\text { activity }\end{array}$ & $\begin{array}{l}\text { Average } \\
\text { O.D. } \pm \text { SD }\end{array}$ & $\begin{array}{l}\text { Biofilm ability } \\
\text { categorization }\end{array}$ \\
\hline S1 & MS & + & $\alpha$ hemolysis & $3.469 \pm 0.057$ & +++ \\
\hline S2 & MLSBi & - & $\gamma$ hemolysis & $3.131 \pm 0.053$ & +++ \\
\hline S3 & MLSBi & + & $\gamma$ hemolysis & $3.661 \pm 0.008$ & +++ \\
\hline S4 & MS & - & $\alpha$ hemolysis & $2.797 \pm 0.192$ & ++ \\
\hline S5 & MLSBi & + & $\beta$ hemolysis & $3.382 \pm 0.171$ & +++ \\
\hline S6 & MS & + & $\beta$ hemolysis & $3.569 \pm 0.020$ & +++ \\
\hline S7 & $\mathrm{S}$ & + & $\alpha$ hemolysis & $3.312 \pm 0.074$ & +++ \\
\hline S8 & MLSBC & - & $\gamma$ hemolysis & $3.300 \pm 0.050$ & +++ \\
\hline S9 & MLSBC & - & $\beta$ hemolysis & $2.123 \pm 0.404$ & ++ \\
\hline S10 & MLSBC & - & $\beta$ hemolysis & $1.993 \pm 0.506$ & ++ \\
\hline
\end{tabular}

MLSBi: inducible MLSB; MLSBc: constitutive MLSB.

*Lipolytic activity was interpreted as negative (-) or positive (+).

**Biofilm production was interpreted as: negative $(-)$, weak $(+)$, moderate $(++)$ strong $(+++)$. 
Table 3. Minimum inhibitory concentration values of different antibiotics

\begin{tabular}{lccc}
\hline \multirow{2}{*}{ Isolates } & \multicolumn{3}{c}{ Minimum inhibitory concentration $(\mathrm{mg} / \mathrm{l})$} \\
\cline { 2 - 4 } & Ciprofloxacin & Gentamycin & Erythromycin \\
& & & \\
\hline S1 & 1 & $\geq 16$ & $\geq 8$ \\
S2 & $\geq 4$ & $\geq 16$ & $\geq 8$ \\
S3 & $\geq 4$ & $\geq 16$ & $\geq 8$ \\
S4 & $\geq 4$ & $\geq 16$ & $\geq 8$ \\
S5 & $\geq 4$ & $\geq 16$ & $\geq 8$ \\
S6 & 2 & 4 & $\geq 8$ \\
S7 & $\geq 4$ & 8 & 2 \\
S8 & $\geq 4$ & $\geq 16$ & $\geq 8$ \\
S9 & $\geq 4$ & $\geq 16$ & $\geq 8$ \\
S10 & $\geq 4$ & 16 & $\geq 8$ \\
\hline
\end{tabular}

concentrations $(500,1500$ and $2000 \mathrm{ppm})$ of different heavy metals used. The recorded results in Table 4 demonstrated that the bacteria can grow at high concentrations of $\mathrm{K}^{+}$and $\mathrm{Mg}^{2+}$. On the other hand, the MTC of heavy metals was evaluated as $500 \mathrm{ppm}$ for all isolates in case of cobalt and iron. For zinc, the MTC was 500 ppm in all isolates except for isolate number 7 which was highly resistant, while in case of copper the MTC was $500 \mathrm{ppm}$ for all isolates except for isolates 2 and 5 which were highly sensitive even in the lowest concentration. Antibiofilm activity of commercial antibiotics

The effect of three antibiotics was studied to inhibit the MRSA strains biofilm formation ability. Different inhibition percentages were showed (Fig. 2). Generally, low biofilm inhibition percentages
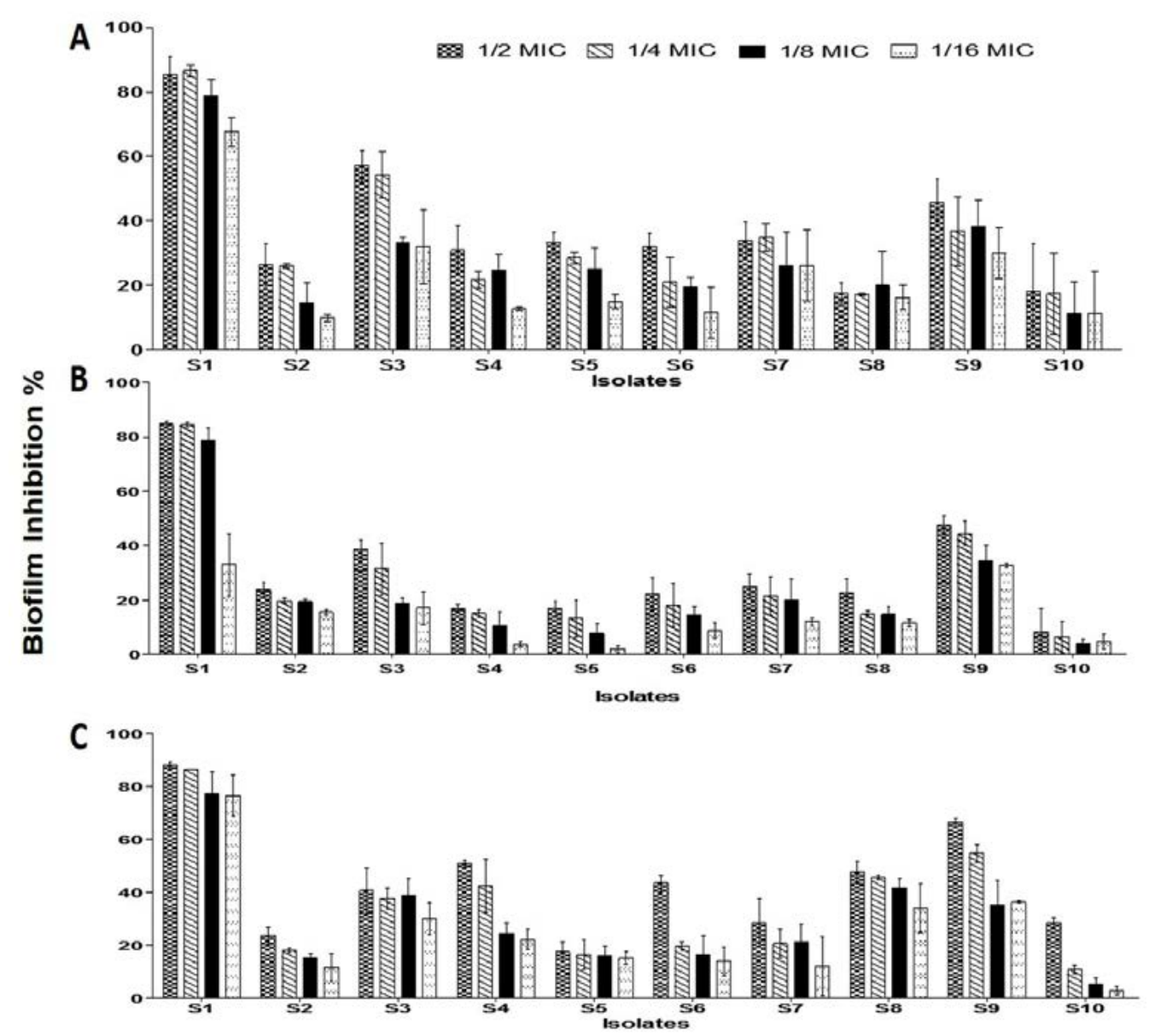

Fig. 2. Effect of different antibiotics concentrations on MRSA strains biofilm formation. (a) Gentamycin (b) Ciprofloxacin and (c) Erythromycin. The bars on the graph represent mean \pm SD as a percentage of biofilm inhibition/ eradication of triplicate independent experiments $(n=2)$. 


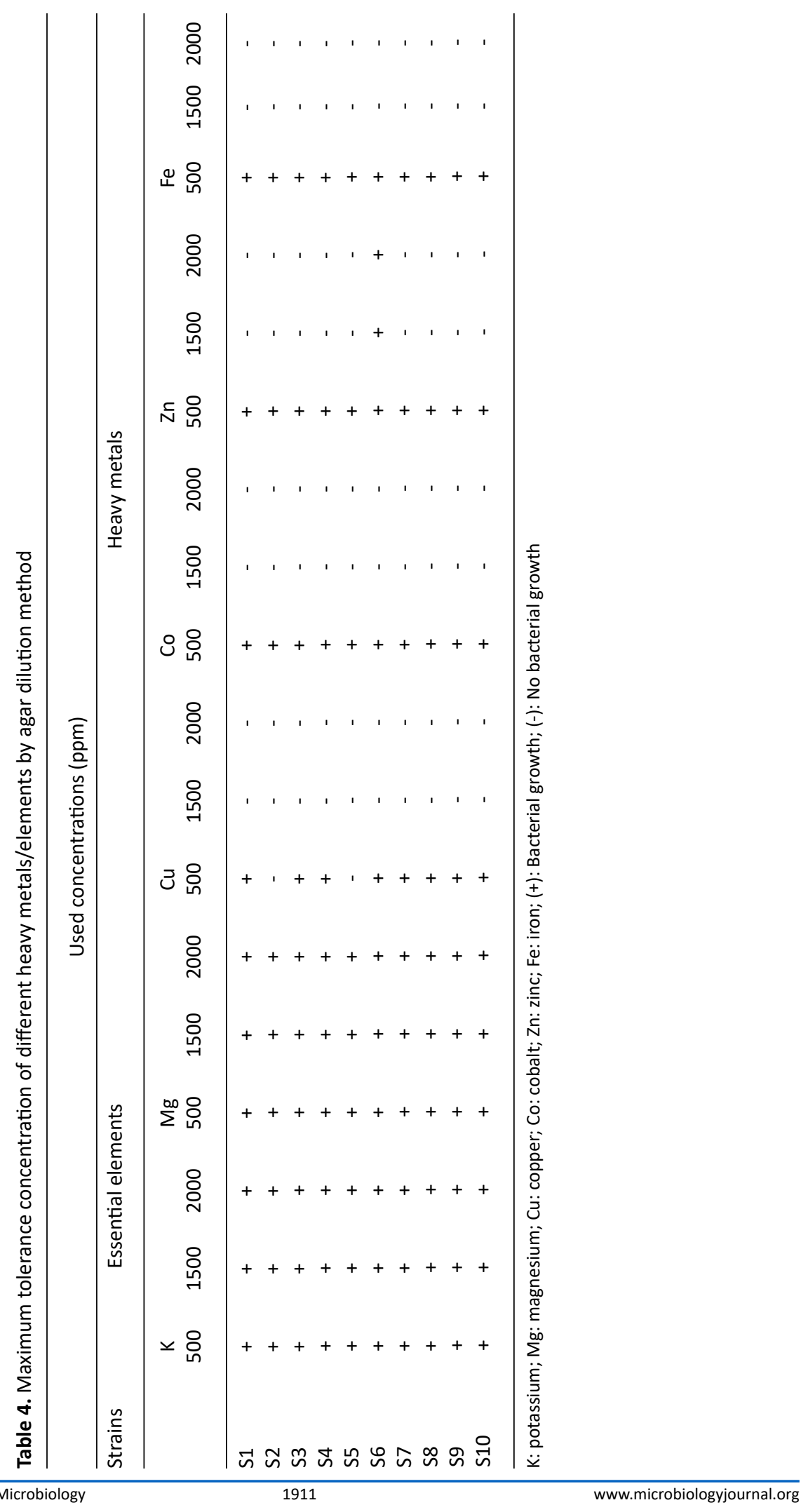




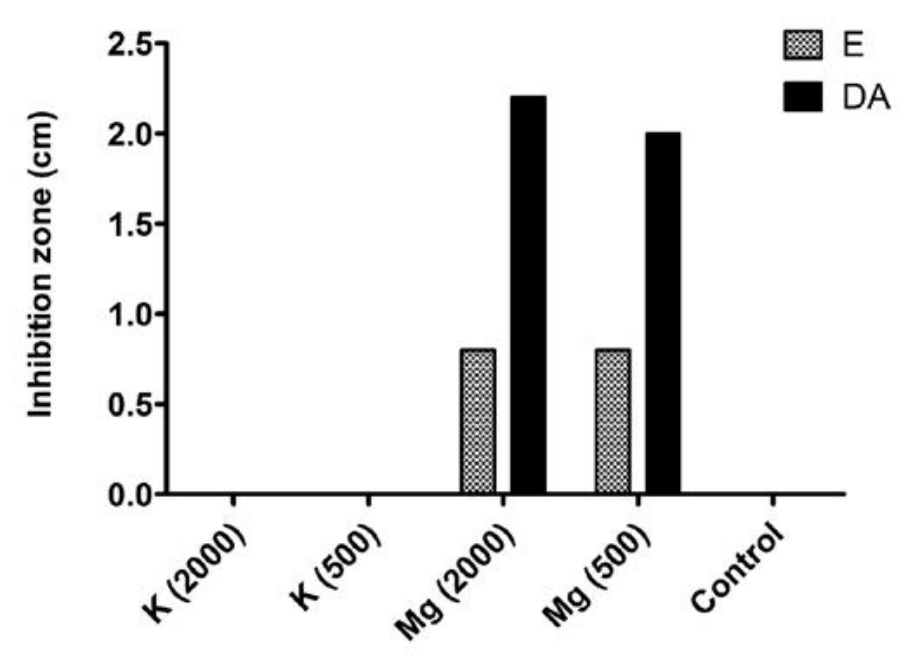

Elements supplemented concentrations (ppm)

Fig. 3. Synergistic effect of potassium (K) and magnesium (Mg) supplementation with antibiotic discs of erythromycin (E) and clindamycin (DA) against MRSA strain (S8).

were observed for the three tested antibiotics, at which the best inhibition percentages observed by using $1 / 2$ MIC antibiotics concentration, followed by $1 / 4,1 / 8$ and $1 / 16$ MICs. The most sensitive isolates which showed reduction in biofilm formation ability were S1, S3 and S9.

Antibiotic/heavy metals synergistic assay

Synergistic activity of $\mathrm{K}^{+}$and $\mathrm{Mg}^{2+}$ at concentrations of 500 and 2000 ppm (Fig. 3), showed that enhanced inhibition zones were detected in case of magnesium supplementation, while on the other hand no zones were detected in case of potassium supplementation.

\section{DISCUSSION}

Recently, Staphylococcus aureus has drawn much attention among researchers due to its adaptation ability to a range of antibiotics causing resistance ${ }^{29}$, and these bacterial characters can complicate infection treatment and control, specially MRSA strains ${ }^{30}$. Over the past few years, reports about MRSA prevalence were obtained showing different prevalence over countries, at which MRSA prevalence of $53.4 \%$ in East Africa ${ }^{29}, 29 \%$ in United Arab Emirates (UAE) ${ }^{31}, 34.2 \%$ in India ${ }^{32}$.

In the present investigation, the antibiotic of $S$. aureus reported a high resistance to ampicillin and amoxicillin/clavulanic by percentages of $100 \%$, followed by resistance to erythromycin (90\%) and ciprofloxacin (60\%). The resulted ciprofloxacin resistance percentage is in agreement with many reported studies, However, noticeable elevated rate of erythromycin resistance was recorded compared to other reports ${ }^{12,33,34}$. On the other hand, the bacteria showed high sensitivity to clindamycin, which is in line with the study reporting $73.2 \%$ sensitivity percentage ${ }^{33}$, but considered higher than the percentage reported in Palestine $(34.8 \%)^{34}$.

Resistance to macrolides, lincosamides, and group B streptogramins is commonly referred to as "MLSB resistance". The erm gene encodes methylation of the $23 \mathrm{~S}$ rRNA-binding site that is shared by these three drug classes ${ }^{10,12}$. Erythromycin and clindamycin are antimicrobials which belong to the MLSB group widely recommended to treat staphylococcal infections ${ }^{35}$. In this study, different MLSB resistance phenotypes percentages for $S$. aureus including $S$, CMLSB, iMLSB and MS respectively were recorded. In literature survey of many countries, it was observed that in India, $64.8 \%$ had cMLSB, 25\% had $\mathrm{iMLSB}$ and $8 \%$ had the MS phenotype among the tested MRSA isolates ${ }^{15}$. In South Ethiopia, inducible clindamycin resistance was detected 
in $19 / 22$ of the erythromycin-resistant strains ${ }^{36}$. The prevalence of iMLSB and CMLSB phenotypes was $11.48 \%$ and $29.25 \%$ respectively, where both phenotypes predominated in MRSA strains were reported ${ }^{37}$. This reported resistance to macrolides is suggested to be due to modification of the bacterial intracellular drug-binding site on the ribosome ${ }^{10}$.

Indeed, several virulence factors involved in the pathogenesis character of $S$. aureus strains have been described in the literature ${ }^{38}$. Because of the bacterial ability to grow in biofilms, this bacterial pathogens exhibited drug tolerance to a broad-spectrum of antibiotics, which is attributed to the biofilm itself. Pathogens are able to produce biofilms, which can be explained by many factors including the decreased permeability of the drug inside the bacterial cells, the appearance of persisting bacteria, and intracellular bacterial survival $^{39}$. In literature, different reports for biofilm occurrence were found, Piechota et al., (2018) reported that strong biofilm was formed by $39.7 \%$ of $\mathrm{MRSA}^{40}$. A percentage of $50 \%$ was demonstrated in another study as weak biofilm producers followed by moderate and strong biofilm ones by $27 \%$ and $23 \%$ respectively ${ }^{41}$. Furthermore, higher biofilm formation was also reported at different percentages of $69.8 \%, 68.3 \%$, and $53.5 \%^{1,5,42}$.

Low inhibition percentages were observed by using different antibiotics concentrations (Fig. 3). Recently, sub-inhibitory concentrations of different commercially used antibiotics were tested on the Staphylococcus aureus biofilms, and as a result different reductions in those biofilms were observed ${ }^{26,43,44}$. Antibiotics at sub-MIC levels were found to affect some biofilm virulence expression, suggesting that it is antibiotic dose dependent $^{28,45}$.

Potentially toxic metal contaminants may interact with ecosystem native inhabitant; therefore those bacteria can develop some mechanisms of tolerance allowing them to survive $^{46}$. This co-occurrence of such antibiotic/ metal resistance has been reported ${ }^{47}$. In this study, high MTC values were recorded, $500 \mathrm{ppm}$ for all isolates, in case of cobalt, iron and zinc (except for isolate 7) in addition to copper (except for isolates 2 and 5). On the other hand, the bacteria were grown normally at elevated concentrations of $\mathrm{K}^{+}$ and $\mathrm{Mg}^{2+}$.
The first-row d-block metal ions, which are manganese $(\mathrm{Mn})$, iron (Fe), cobalt (Co), nickel $(\mathrm{Ni})$, copper $(\mathrm{Cu})$, and zinc $(\mathrm{Zn})$, are essential micronutrients. $\mathrm{Cu}$ and $\mathrm{Zn}$ are now recognized to be involved in the phagosomal killing of bacteria engulfed by macrophages, defined as an important defense mechanism ${ }^{48}$. The rapid killing of bacteria is thought to be due to cellular damage caused by very high concentrations of $\mathrm{Cu}$ dissolving from the surface, which causes membrane disturbance and rupture, coupled with internal oxidative burst due to the generation of ROS leading to further cellular destruction, including degradation of plasmid and chromosomal DNA ${ }^{49}$.

According to our results, no effect for both $\mathrm{K}^{+}$and $\mathrm{Mg}^{2+}$ was detected even in the highest concentration. On the other hand, by using predictable synergistic disc diffusion method, $\mathrm{Mg}^{2+}$ supplementation at concentrations of 500 and 2000 ppm showed enhancement activity for both antibiotics used (Fig. 2). $\mathrm{K}^{+}$is responsible for many cellular processes, including regulation of intracellular $\mathrm{pH}$, maintenance of turgor, and activation of enzymes ${ }^{50}$. Whereas, $\mathrm{Mg}^{2+}$ is well known to be important in the normal homeostatic mechanisms of the cells ${ }^{51,52}$.

\section{CONCLUSION}

Our results reveal high heavy metal tolerance among antibiotic-resistant MRSA strains, in addition to the presence of virulence factors such as biofilm formation and enzymatic activity (hemolytic and lipolytic). The supplementation of $\mathrm{Mg}$ at different concentrations (500 and 2000 ppm) showed synergistic activity with the antibiotics; erythromycin and clindamycin. To enhance the antibiotic activities, upcoming studies must be focused on the combination of a sub-inhibitory concentration of different heavy metals with the available antibiotics.

\section{ACKNOWLEDGMENTS}

None.

\section{CONFLICT OF INTEREST}

The authors declare that there is no conflict of interest.

\section{AUTHORS' CONTRIBUTION}

All authors listed have made a substantial, 
direct and intellectual contribution to the work, and approved it for publication.

\section{FUNDING}

None.

\section{ETHICS STATEMENT}

Not applicable.

\section{DATA AVAILABILITY}

All datasets generated or analyzed during this study are included in the manuscript.

\section{REFERENCES}

1. Neopane P, Shrestha R, Uehara O, Abiko Y. In vitro biofilm formation by Staphylococcus aureus isolated from wounds of hospital-admitted patients and their association with antimicrobial resistance. Int J Gen Med. 2018;11:25-32. doi: 10.2147/IJGM.S153268

2. Jafari-Sales A, Farhadi F, Ezdiyadi M, Tarbiat-Nazloo D. Study of antibiotic resistance pattern in methicillinresistant Staphylococcus aureus isolated from clinical samples of hospitals in Tabriz - Iran. Int J Biomed Public Heal. 2018;1(2):71-75.

3. Metwally M, Ali S, Khatab I, El-Sayed M. Antibacterial Potential of some Seaweeds Species to Combat Biofilm-producing Multi-drug Resistant Staphylococcus aureus of Nile Tilapia. Egypt J Bot. 2020;60(1):9-24. doi: 10.21608/ejbo.2019.6829.1275

4. Oogai $Y$, Matsuo $M$, Hashimoto $M$, Kato F, Sugai $M$, Komatsuzawa $\mathrm{H}$. Expression of Virulence Factors by Staphylococcus aureus Grown in Serum. Appl Environ Microbiol. 2011;77(22):8097-8105. doi: 10.1128/ AEM.05316-11

5. Haddad O, Merghni A, Elargoubi A, Rhim H, Kadri Y, Mastouri M. Comparative study of virulence factors among methicillin resistant Staphylococcus aureus clinical isolates. BMC Infect Dis. 2018;18:560. doi: 10.1186/s12879-018-3457-2

6. Mohamed SH, Khalil MS, Azmy M. In vitro Efficiency of Ampicillin, Thymol and Their Combinations against Virulence Strains of Klebsiella pneumoniae. Int J Pharm Res. 2019;11(3):315-321.

7. Mohamed SH, Khalil MS, Mohamed MSM, Mabrouk MI. Prevalence of antibiotic resistance and biofilm formation in Klebsiella pneumoniae carrying fimbrial genes in Egypt. Res J Pharm Technol. 2020;13(7):30513058. doi: 10.5958/0974-360X.2020.00542.9

8. Watters CM, Burton T, Kirui DK, Millenbaugh NJ. Enzymatic degradation of in vitro Staphylococcus aureus biofilms supplemented with human plasma. Infect Drug Resist. 2016;9:71-78. doi: 10.2147/IDR. S103101

9. Mohamed SH, Mohamed MSM, Khalil MS, Mohamed WS, Mabrouk MI. Antibiofilm activity of papain enzyme against pathogenic Klebsiella pneumoniae. J Appl Pharm Sci. 2018;8(06):163-168. doi:10.7324/ JAPS.2018.8621.

10. Ii JSL, Jorgensen JH. Inducible Clindamycin Resistance in Staphylococci : Should Clinicians and Microbiologists be Concerned ? Antimicrob Resist. 2005;40(2):280285. doi: $10.1086 / 426894$

11. Mohamed SH, Khalil MS. DNA Sequencing of bla SHV Genes among Uropathogenic Klebsiella pneumoniae Harboring bla CTX-M-15. Int J Pharm Res. 2020;12:443449. doi: 10.31838/ijpr/2020.12.04.057

12. Ahmed MO, Abuzweda AR, Alghazali MH, et al. Misidentification of methicillin-resistant Staphylococcus aureus (MRSA) in hospitals in Tripoli, Libya. Libyan J Med. 2010;5:5230. doi: 10.3402/ljm. v5i0.5230.

13. Navidinia M. Detection of inducible clindamycin resistance (MLSBi) among methicillin- resistant Staphylococcus aureus (MRSA) isolated from health care providers. J Paramed Sci. 2015;6(1):91-96.

14. Kareem SM, Jubori SSA-, Ali M. Prevalence of erm Genes among Methicillin Resistant Staphylococcus aureus MRSA Iraqi Isolates. Int J Curr Microbiol App Sci. 2015;4(5):575-585.

15. Singh $T$, Deshmukh AB, Chitnis V, Bajpai T. Inducible clindamycin resistance among the clinical isolates of Staphylococcus aureus in a tertiary care hospital. Int J Heal Allied Sci. 2016;5(2):111-114. doi:10.4103/2278$344 X .180428$.

16. Talebi G, Hashemia A, Goudarzi H, et al. Survey of ermA, erm $B$, erm $C$ and mecA genes among Staphylococcus aureus isolates isolated from patients admitted to hospitals in Tehran, Iran by PCR and sequencing. Biomed Res. 2019;30(2):259-263. doi: 10.35841/ biomedicalresearch.30-18-1152

17. Baker-austin C, Wright MS, Stepanauskas R, Mcarthur JV. Co-selection of antibiotic and metal resistance. TRENDS Microbiol. 2006;14(4):176-182. doi:10.1016/j. tim.2006.02.006

18. Chen S, Li X, Sun G, Zhang Y, Su J, Ye J. Heavy Metal Induced Antibiotic Resistance in Bacterium LSJC7. Int J Mol Sci. 2015;16(10):23390-23404. doi:10.3390/ ijms161023390.

19. Eggers S, Safdar N, Malecki KMC. Heavy metal exposure and nasal Staphylococcus aureus colonization : analysis of the National Health and Nutrition Examination Survey (NHANES). Environ Heal. 2018;17(2):1-10. doi: 10.1186/s12940-017-0349-7.

20. Mohamed MSM, Abdallah AA, Mahran MH, Shalaby M. Potential Alternative Treatment of Ocular Bacterial Infections by Oil Derived from Syzygium aromaticum Flower (Clove). Curr Eye Res. 2018;43(7):873-881. doi: 10.1080/02713683.2018.1461907.

21. The Clinical and Laboratory Standards Institute. Performance Standards for Antimicrobial Susceptibility Testing CLSI Supplement M100-S26. 2016.

22. Dash M. Detection of inducible and constitutive clindamycin resistance among Staphylococcus aureus isolates in a tertiary care hospital, Eastern India. Avicenna J Med. 2016;6(3):75-80. doi: 10.4103/22310770.184066

23. Mohammad HH. Phenotypic Investigation for Virulence factors of Pyocine producing Pseudomonas aeruginosa Isolated from Burn Wounds, Iraq. Int J Sci Eng Res. 2013;4(7):2114-2121.

24. Hasan R, Acharjee M, Noor R. Prevalence of vancomycin 
resistant Staphylococcus aureus (VRSA) in methicillin resistant $S$. aureus (MRSA) strains isolated from burn wound infections. Tzu Chi Med J. 2016;28(2):49-53. doi: 10.1016/j.tcmj.2016.03.002.

25. Mohamed SH, Salem D, Azmy M, Fam NS. Antibacterial and antibiofilm activity of cinnamaldehyde against carbapenem-resistant Acinetobacter baumannii in Egypt : In vitro study. J App/ Pharm Sci. 2018;8(11):151156. doi: 10.7324/JAPS.2018.81121.

26. Mohamed M, Mostafa H, Mohamed S, El-Moez SA, Kamel Z. Combination of Silver Nanoparticles and Vancomycin to Overcome Antibiotic Resistance in Planktonic/Biofilm Cell from Clinical and Animal Source. Microb Drug Resist. 2020. doi: 10.1089/ mdr.2020.0089.

27. Afzal AM, Rasool MH, Waseem M, Aslam B. Assessment of heavy metal tolerance and biosorptive potential of Klebsiella variicola isolated from industrial effluents. AMB Express. 2017;7(184):184. doi: 10.1186/s13568017-0482-2.

28. Mohamed SH, Mohamed MSM, Khalil M, Azmy $M$, Mabrouk M. Combination of essential oil and ciprofloxacin to inhibit/eradicate biofilms in multidrugresistant Klebsiella pneumoniae. J Appl Microbiol. 2018;125(1):84-95. doi: 10.1111/jam.13755.

29. Wangai FK, Masika MM, Maritim MC, Seaton RA. Methicillin-resistant Staphylococcus aureus (MRSA) in East Africa: red alert or red herring? BMC Infect Dis. 2019;19:596. doi: 10.1186/s12879-019-4245-3

30. Kateete DP, Bwanga F, Seni J, et al. CA-MRSA and HAMRSA coexist in community and hospital settings in Uganda. Antimicrob Resist Infect Control. 2019;8:94. doi: 10.1186/s13756-019-0551-1

31. Jalaf M Al, Fadali H, Alanee $\mathrm{R}$, et al. Methicillin resistant Staphylococcus aureus in emergency department patients in the United Arab Emirates. BMC Emerg Med. 2018;18:12. doi: 10.1186/s12873-018-0164-7

32. Perala BMK, Koripella RL, Vani TMSS, Lakshmi N. Prevalence of Methicillin Resistant Staphylococcus aureus in A Tertiary Care Hospital. J Dent Med Sci. 2016;15(5):29-31. doi: 10.9790/0853-1505062931.

33. Abdullahi N, Iregbu KC. Methicillin-Resistant Staphylococcus aureus in a Central Nigeria Tertiary Hospital. Ann Trop Pathol. 2018;9(1):6-10. doi: 10.4103/atp.atp_37_17

34. Hadyeh E, Azmi K, Seir RA, Abdellatief I, Abdeen Z. Molecular Characterization of Methicillin Resistant Staphylococcus aureus in West Bank-Palestine. Front Public Heal. 2019;7:130. doi: 10.3389/ fpubh.2019.00130.

35. Martins MA, Santos S de LV dos, Leao LSN de O, Araujo NP, Bachion MM. Prevalence of resistance phenotypes in Staphylococcus aureus and coagulase-negative isolates of venous ulcers of primary healthcare patients. Rev Soc Bras Med Trop. 2012;45(6):717-722. doi: 10.1590/S0037-86822012000600012

36. Mama M, Aklilu A, Misgna K, Tadesse M, Alemayehu E. Methicillin-and Inducible Clindamycin-Resistant Staphylococcus aureus among Patients with Wound Infection Attending Arba Minch Hospital, South Ethiopia. Int J Microbiol. 2019;2019:2965490. doi: $10.1155 / 2019 / 2965490$
37. Adhikari RP, Shrestha S, Barakoti A, Amatya R. Inducible clindamycin and methicillin resistant Staphylococcus aureus in a tertiary care hospital, Kathmandu, Nepal. BMC Infect Dis. 2017;17:483. doi:10.1186/s12879-0172584-5.

38. Bien J, Sokolova O, Bozko P. Characterization of Virulence Factors of Staphylococcus aureus : Novel Function of Known Virulence Factors That Are Implicated in Activation of Airway Epithelial Proinflammatory Response. J ofPathogens. 2011;2011:601905. doi:10.4061/2011/601905.

39. Mohamed SH, Elshahed MMS, Saied YM. Evaluation of Honey as an antibacterial agent against drug-resistant uropathogenic E. coli strains. Res J Pharm Tech. 2020;13(8):3720-3724.

40. Piechota MB, Kot B, Frankowska-maciejewska A, Gru A, Wo A. Biofilm Formation by Methicillin-Resistant and Methicillin-Sensitive Staphylococcus aureus Strains from Hospitalized Patients in Poland. Biomed Res Int. 2018;2018:4657396. doi: 10.1155/2018/4657396

41. Sohail M, Latif Z. Molecular analysis, biofilm formation, and susceptibility of methicillin-resistant Staphylococcus aureus strains causing community- and health care-associated infections in central venous catheters. Rev Soc Bras Med Trop. 2018;51(5):603-609. doi:10.1590/0037-8682-0373-2017.

42. Jeong-ok $C$, Jae I, Jung $S$, et al. Investigation of Biofilm Formation and its Association with the Molecular and Clinical Characteristics of Methicillinresistant Staphylococcus aureus. Osong Public Heal Res Perspect. 2013;4(5):225-232. doi:10.1016/j. phrp.2013.09.001.

43. Yang B, Lei Z, Zhao Y, et al. Combination Susceptibility Testing of Common Antimicrobials in Vitro and the Effects of Sub-MIC of Antimicrobials on Staphylococcus aureus Biofilm Formation. Front Microbiol. 2017;8:2125. doi: 10.3389/fmicb.2017.02125.

44. Lazaro-Diez M, Remuzgo-Martinez S, RodriguezMirones C, et al. Effects of Subinhibitory Concentrations of Ceftaroline on MethicillinResistant Staphylococcus aureus (MRSA) Biofilms. PLoS One. 2016;11(1):e0147569. doi:10.1371/journal. pone.0147569.

45. Haddadin RNS, Saleh S, Al-Adham ISI, Buultjens TEJ, Collier PJ. The effect of subminimal inhibitory concentrations of antibiotics on virulence factors expressed by Staphylococcus aureus biofilms. J Appl Microbiol. 2010;108(4):1281-1291. doi: 10.1111/j.1365-2672.2009.04529.x.

46. Mohamed MS, El-Arabi NI, El-Hussein A, El-Maaty SA, Abdelhadi AA. Reduction of chromium-VI by chromium-resistant Escherichia coli FACU: a prospective bacterium for bioremediation. Folia Microbiol.(Praha). 2020;65(4):687-696: doi: 10.1007/ s12223-020-00771-y.

47. Yazdankhah S, Skjerve E, Wasteson Y. Antimicrobial resistance due to the content of potentially toxic metals in soil and fertilizing products. Microb Ecol Health Dis. 2018;29:1548248. doi:10.1080/1651223 5.2018.1548248.

48. Djoko KY, Ong CY, Walker MJ, Mcewan AG. The Role of Copper and Zinc Toxicity in Innate Immune 
Defense against Bacterial Pathogens. I Biol Chem. 2015;290(31):18954-18961. doi:10.1074/jbc. R115.647099.

49. Grass G, Rensing C, Solioz M. Metallic Copper as an Antimicrobial Surface. Appl Environ Microbiol. 2011;77(5):1541-1547. doi:10.1128/AEM.02766-10.

50. Schramke H, Laermann V, Tegetmeyer HE, Brachmann A, Jung K, Altendorf K. Revisiting regulation of potassium homeostasis in Escherichia coli: the connection to phosphate limitation. Microbiology
Open. 2017;6(3):e438. doi: 10.1002/mbo3.438.

51. Saris NL, Mervaala E, Karppanen H, Khawaja JA, Lewenstam A. Magnesium An update on physiological, clinical and analytical aspects. Clin Chim Acta. 2000;294(1):1-26. doi: 10.1016/S00098981(99)00258-2

52. Staiger MP, Pietak AM, Huadmai J, Dias G. Magnesium and its alloys as orthopedic biomaterials: A review. Biomaterials. 2006;27(9):1728-1734. doi:10.1016/j. biomaterials. 2005.10.003 